\title{
Research on the Overseas Listing of VIE Mode
}

\author{
Yusheng Yang \\ ZheJiang University \\ GuangHua Law School \\ Hangzhou, China \\ 11701044@zju.edu.cn
}

\begin{abstract}
The VIE model is an important way for Chinese enterprises to be listed abroad, but there are many defects. Under the current regulatory system, it is impossible to get effective supervision and produce many risks. In view of the problem of VIE model overseas listing, it defines its basic connotation, analyzes its general structure and basic operating mechanism, and explores the laws and regulations. To regulate it, clarify its enterprise risk under its structural mode, and put forward relevant countermeasures for specific risks.
\end{abstract}

Keywords-VIE mode; rules and regulation; business risk; measure

\section{INTRODUCTION}

Under the VIE model, is a wholly foreign owned enterprise, offshore company signed a series of agreements with domestic company, will be listed abroad subject that is associated with domestic operating entities, listed abroad subject in listed abroad, so as to realize indirect overseas listing of domestic operating subject, to avoid the foreign investment industrial guidance catalogue for restricted and prohibited class restrict foreign investment in industry. However, as there are many defects in the VIE model, it cannot be effectively regulated under the current regulatory system, resulting in a lot of risks. Therefore, it is necessary to establish legal supervision of the VIE model.

\section{OVERVIEW OF THE VIE MODE}

VIE mode (Variable Interest Entities, generally referred to as the protocol control mode in China) means that overseas listed entities have a series of agreements with domestic operating entities to link overseas listed entities with domestic operating entities and to list overseas. The main body is listed overseas, thus achieving a red-chip listing model for indirect overseas listing of domestic operating entities.

\section{A. The connotation of VIE mode}

The word "VIE" is a combination of the first letters of the three words in the English "Variable Interest Entities", which is translated as "variable interest entities" in Chinese. The term was first seen in the US accounting rules FIN46 revised after the 2001 Enron Incident, which responds to the development of corporate control models and compensates for the omissions of previous corporate financial accounting rules.[1]

It refers to the controlling interest of the investment enterprise, but the interest does not come from the majority voting rights. The concept of a variable interest entity is similar to the concept of a Special Purpose Entity (SPE). The purpose of establishing an SPE company is mostly to accomplish certain specific short-term tasks, such as avoiding financial risks (usually bankruptcy) or other regulatory risks. In the 1980s and 1990s, some companies discovered ways to hide their liabilities on the balance sheet by setting up "special purpose entities." It was this off-balance sheet financing that triggered an accounting crisis in the early 21st century. . After the Enron incident, the US Financial Accounting Standards Board (FASB) urgently issued Interpretation Letter No. 46 "Consolidation of Variable Interest Entities", which stipulates that the "first beneficiary" who bears the main risks and benefits of VIE needs to put VIE Assets are consolidated into their financial statements and disclosed as assets in the table.

The VIE structure is generally called the protocol control mode in the domestic industry. It is a legal structure in which a shell company established and listed overseas relies on contractual arrangements to control domestic entity companies, thereby realizing the indirect listing of domestic entities. Under the agreement control mode, the connection between the overseas listed entity and the domestic entity that actually operates the business is not an equity relationship, but a contractual relationship. Although agreement control is a kind of contractual arrangement, VIE is an accounting term. The two are completely different concepts. However, in the process of listing overseas by Chinese enterprises, they are often regarded as one and play a role in evading supervision.

\section{B. The usual architecture of the VIE structure}

The VIE structure is usually composed of a three-part architecture.

(1) Overseas listed entities Due to various tax incentives, registration conveniences, etc., tax havens such as Cayman and Hong Kong Shell may have multiple and multiple structures.

(2) Domestic wholly foreign-owned subsidiaries are the same group of Chinese shareholders, and their interests are highly consistent to ensure the stability of the VIE structure.

(3) Domestic operating entity companies are usually holders of restricted foreign business licenses.

\section{VIE basic operating mechanism}

(1)The founder of a domestically listed company that intends to pass the VIE structure establishes an offshore company in the BVI (British Virgin Islands) or the Cayman Islands.

(2)The offshore company and VC (risk investors), PE (private equity investors) and other shareholders, together form 
a company (usually registered in the Cayman Islands) as the main body of the listing.

(3)The proposed listing entity will then establish or acquire a shell company in Hong Kong.

(4)Hong Kong Shell Company has established a whollyowned subsidiary (WFOE) in the territory.

(5)The wholly-owned subsidiary has signed a series of agreements with the entity companies operating in the domestic business to achieve control over the domestic enterprises' decision-making, management and profit.

\section{The practice of VIE structure in China}

Since the first Sina company adopted the VIE structure for the first time to go to the United States in April 2000, the overseas listing model of VIE structure has become a model for private enterprises in China, especially the Internet companies, to choose overseas. Since then, Sohu, NetEase, Tencent, Baidu, Qihoo 360, Youku and other Internet information companies have followed suit and successfully implemented overseas listing. Not only that, the model is also promoted to the education and training field represented by the New Oriental, with the media published by Focus Media, Vision China and so on, as well as in many fields, such as consumption and radio and television. As the model was first created by Sina, it was also known as the Sina model, Sina structure or Sina architecture. Reuters's data show that 95 of the more than 200 Chinese companies listed on the New York stock exchange and NASDAQ are VIE structured.

\section{LEGAL REgUlation OF CHINA'S VIE MODEL}

The use of the VIE structure overseas listing model by domestic enterprises not only circumvents the restrictions of China's laws on foreign investment access and overseas investment and financing, but also causes VIE to return to investment, return mergers and acquisitions, and avoid foreign exchange flow management in order to make VIE obtain the performance required for listing. Such risks will bring security risks to the country's economic development. At present, China does not have laws and regulations that specifically regulate the overseas listing model of the VIE structure. The regulation of the overseas listing model of the VIE structure is mainly reflected in the laws and regulations on foreign investment, foreign mergers and acquisitions, foreign exchange flows, and overseas investment and financing.

These laws and regulations can be divided into two categories according to whether it is clearly applicable to the VIE structure overseas listing model: First, the provisions clearly apply to the relevant enterprises in the protocol control (VIE structural model), and the second is that the provisions are not clearly defined but applicable. It is also applicable to the regulations of enterprises related to the overseas listing model of VIE structure.

\section{ENTERPRISE RISK UNDER VIE STRUCTURAL MODEL}

The VIE model has the characteristics of typical "curve investment" and "curve distribution". Through complicated contractual arrangements, stakeholders realize a win-win situation for enterprise development and shareholder benefits.
However, the instability of the VIE model itself has also buried hidden dangers that may break out at any time. The VIE model is by no means an once-in-a-lifetime elixir, and the risks it poses need to be fully vigilant.

\section{A. Agreement legality risk}

The essence of the VIE structure is to achieve control over the enterprise through a series of complicated contractual arrangements, in order to circumvent China's foreign investment access restrictions and related regulations on mergers and acquisitions. The legal acts involved are legally called off-laws, that is, the act of circumventing the law refers to the use of devious means to circumvent the forcible regulations, but the freedom of contract is used in order to achieve the effect that the law does not allow.[2] However, it is worth noting that the civil law of civil law system usually does not make special provisions on the law-breaking behavior, and whether the legal act is invalid because it is out of the law is a matter of legal interpretation.

Once the VIE agreement is deemed invalid by the court, the chain of the listed company and the entity company breaks, which will produce a series of chain reactions: the stocks of overseas listed companies purchased by overseas investment institutions and the general public are actually only the shares of the shell companies, and do not have any Value, the interests of investors are thus impaired; if the founder or the new shareholder of the domestic operating entity takes advantage of the effectiveness of the control agreement and refuses to perform the obligation, the shareholders of the overseas company not only lose control of the domestic entity, even the other The liability for breach of contract is difficult to pursue. At this point, the control protocol has become a piece of paper, meaningless.[3]

\section{B. Policy compliance risk}

Although the VIE model has gone through more than a decade under the government's acquiescence, some industries involving national financial security have begun to reject the VIE model. The Measures for the Administration of Payment Services for Non-Financial Institutions implemented on September 1, 2010 (People's Bank of China Order [2010] No. 2) require all non-financial institutions engaged in online payment to obtain a "payment business license" to become a legal payment. The organization can engage in payment business, which specifically states: "The business scope of foreigninvested payment institutions, the qualifications of overseas investors and the proportion of capital contribution shall be separately prescribed by the People's Bank of China and submitted to the State Council for approval."

For the 2011 Alipay incident, Ma Yun's conclusion was: "Imperfect, but the only correct." In order to ensure that Alipay can obtain a license, he chose to strictly abide by national laws, leaving no trace of embarrassment, even if the price paid is a violation of the spirit of the contract. "The allegations." it can be seen that although there are no laws and regulations to define the legality of the VIE structure so far, the Chinese government adopts a tacit attitude to allow the use of the VIE structure for more than a decade, but the relevant departments can still exercise discretion to the VIE structure. The scope of application is regulated. Once the relevant national ministries 
and commissions issue corresponding regulations, it is possible to have an impact on the company adopting the VIE structure, and even cause a fatal blow to the actual operation of the company.

\section{Corporate governance structure risk}

Under the VIE structure, the authorized representative of the overseas listed entity, the chairman and legal representative of the WFOE (Wholly Foreign Owned Enterprise) and the chairman and legal representative of the business company are generally held by the founder and the founder holds The company's license, official seal and financial seal. China's current legal representative system and official seal system, resulting in "who grabs the official seal, who takes the initiative; who is the legal person, who represents the company" irrational situation often occurs, and the design of such a corporate governance structure in the VIE model So that the WFOE and domestic business companies are under the actual control of the founders.

Since the domestic business company is only controlled by the WFOE agreement, the control intensity is far less than the equity control, and the WFOE is under the actual control of the founder, which makes it easy for foreign investors to lose the actual participation management right for the domestic business company. Although foreign investors appoint directors or financial controllers in business companies, in the event of a dispute, these individuals appointed by foreign investors are often forcibly evicted by the founding team or face embarrassing situations in which they are unable to exercise their powers. This unreasonable corporate governance structure gives the founder a great degree of freedom in the operation of the business company. In the process of long-term control, it can transfer the core assets of the company through related transactions, unauthorized borrowing, and external guarantees. Feel free to take up company assets and turn the company into your own cash machine.[4] When foreign investors discover the company's asset impairments, they have already lost control of the company.

\section{Risk of information disclosure}

Most entities adopting the VIE model rely on overseas listed companies to complete financing, which leads to the company's inevitable supervision of corporate information disclosure. For example, companies listed in the US need to disclose information not only in accordance with the relevant regulations of the US Securities and Exchange Commission (SEC), but also in strict compliance with the US Standard Accounting Standards (FIN46). Obviously, this merger follows the accounting principle of "substantially more important than form" , but the question that arises is whether the domestic enterprises that are VIE entities should incorporate which entities or businesses they control into the country. What is the report of the listed company? If there is a possibility of selection in this part, it will inevitably affect the relevant financial information of the overseas listed company that incorporates the VIE entity into the report, and this will lead to disputes, and the question of the company's challenge to New Oriental is just the result.

\section{MEASURES FOR ENTERPRISES TO COPE WITH VIE STRUCTURAL MODEL RISKS}

In the VIE structural model, subjects whose interests are harmed due to risk explosion can be divided into two categories: founders and investors. Among them, the founder may be like Baosheng Steel. Because the VIE structure was denied by the government and declared to go bankrupt overseas, it is also possible that the credit crisis will occur like New Oriental, and the VIE model will be buried under the current regulatory system in China. For the former, companies can only abandon the VIE structure and "make another way" to complete the listing intention. In recent years, there are also such cases, such as in time Department Store, Shandong Borun, etc. As for the latter, the founders of the company need to change their concepts and strengthen their information. The transparency of public disclosure, especially in the domestic situation, whether the information disclosure or the integrity of the integrity system needs to be improved, only by allowing overseas investors to see clearly, can they eliminate their doubts and effectively prevent short-selling institutions. Malicious attacks, thus avoiding the high cost of "unnecessary" doubts and accusations.

In the past, once a dispute arises, the only remedy that an investor can obtain is to file a lawsuit and investigate the other party' s liability for breach of contract. However, the VIE model that has been swimming in the legal gray area is very likely to face a situation that is not recognized by the court. In the meantime, the value of investors in overseas companies is short-selled, their interests will be harmed and even basic rights and interests will not be guaranteed by law. So far, there are no public precedents in the domestic courts that directly involve the VIE structure. However, the VIE disputes that were previously decided by arbitration and the jurisprudence that the Supreme Court concluded at the end of 2012, which is very similar to the VIE model, have placed the VIE model very passive position.

In order to avoid or spread the risk of the VIE architecture as much as possible, investors can learn more about the founder of the target company through more detailed legal due diligence, commercial due diligence and special management interviews before investing, and strive to do it early. Prevent and control risks.[5]

On the other hand, it is possible to gain more effective control over the operations of domestic entities by improving the investment structure and institutional arrangements between investors and founders. At the level of VIE structural improvement, it is specifically required to be implemented through the setting of important terms of the investment agreement. The specific performance is as follows: (1)Set the priority clause of the investment fund shareholders, including the priority of the appointed directors and senior executives, the priority of the voting rights, the priority of the profit distribution, etc.; (2)Set up a reasonable official seal use and management system, and set up the replacement or abolition of the official seal. The clauses prevent the executives from illegally holding the official seal and infringe on the interests of the company; (3) setting up the system of appointment and dismissal of the legal representative, avoiding the situation in 
which the investor cannot actually control the company due to failure to complete the legal person change procedure after the shareholders meeting is removed; (4)Set the control clause of the board of directors, the investor has the right to appoint the director to enter the operating company's board of directors to participate in the operation and management, and enjoy the veto of the major issues, to prevent the founder from completely controlling the operation of the operating company.

In addition, some agreement arrangements can be used to enable investors to obtain relief when their interests are damaged. For example, investment funds participate in the management of WFOE, avoiding the fact that the founder actually controls the operation of the VIE structure, and guarantees that the founder defaults or infringes on the company's interests. At the same time, it can trigger the implementation of remedies for equity pledge and breach of contract, and avoid VIE failure;[6]investors can replace single cash shares with more flexible contract instruments such as convertible bonds, once the founder or investor cannot fully perform the business The liability obligation, then it may trigger the conditional setting of financial instruments such as convertible bonds, and the party whose interests are damaged will be compensated.

\section{CONCLUSION}

As we all know, the construction of China's capital market has a long way to go. In the short term, in the attitude towards the VIE structure, we should distinguish between state-owned enterprises and private enterprises, and can strictly regulate the state-owned enterprises, but should take a relaxed attitude towards the VIE of the private enterprises. But in the long run, the key is to build a smooth domestic financing channel, especially the standard of capital market, and gradually establish and improve the multi-level capital market system. At the same time, we should reduce the threshold of entering the market, simplify the process of listing and reduce the cost of financing. At the same time, we should strengthen the construction of the legal system of the capital market, improve the supervision mode of the capital market, and form a more standard, safer and more attractive capital market, which is the "cure" way.

\section{REFERENCES}

[1] Fu Jun. Research on the legal system of overseas indirect listing. Peking University Press, 2010.

[2] Wang Qian. On the legal form to cover the behavior of illegal purposes [D]. Nanjing University Master's Thesis, 2011.

[3] Wang Zejian. General Princip les of Civil Law [M]. China University of Political Science and Law Press, 2000.

[4] Ding Wei, Sun Chao. Satan VIE.IT Times Weekly, 2011 (21)

[5] Yu Shi. The VIE twists and turns of the Internet [J]. Securities Guide, 2011 (11).

[6] Zhang Long. Supervision of overseas listing of Chinese enterprises. China Financial Publishing House, 2011. 